\title{
Locos y simples de Cristo en las letras de la Contrarreforma: vindicación de un tema hagiográfico*
}

Fools and Simpletons for the Christ in the Literature of the Counter-Reformation: Vindication of a Hagiographic Subject

JosÉ ARAgÜÉs AldAZ

Departamento de Lingüística y Literaturas Hispánicas

RECIBIDO: 24 DE JULIO DE 2019 Instituto de Patrimonio y Humanidades

Universidad de Zaragoza

C/ Pedro Cerbuna s/n. Zaragoza, 50009

jaragues@unizar.es

Orcid ID 0000-0002-8169-9786

Resumen: La figura del "loco o simple de Cristo" (el santo sometido al escarnio público a causa de una aparente estulticia, bajo la que se esconde la sabiduría de Dios) aflora en la tradición hagiográfica oriental, para asomar de una manera más discontinua en las letras de Occidente. En la frontera entre los siglos XVI y XVII, algunas obras (como el tratado De simplici obedientia del jesuita Matthaeus Rader, el Flos Sanctorum de Alonso de Villegas o varias "comedias de santos" de Lope de Vega) rescataron las biografías de esos santos "extravagantes", y con ellas todos los ecos de una perfección basada en la inversión de las apariencias del saber. El estudio explora la presencia de ese motivo hagiográfico -el de la estulticia sagrada- en aquellos y otros textos coetáneos, como preámbulo de una más ambiciosa indagación acerca del lugar que el tema pudo haber ocupado en el discurso de la Contrarreforma.

Palabras clave: Locos por Cristo. Simples. Obediencia. Matthaeus Rader. Lope de Vega.
Abstract: The archetype of the "fool (or simpleton) for the Christ" (the saint subjected to public derision because of an apparent stupidity under which sacred wisdom hides) occupies an essential place in the Eastern hagiographic tradition, but appears less often in Western literature. Some works written on the border between the sixteenth and seventeenth centuries (such as the treatise De simplici obedientia by the jesuit Matthaeus Rader, the Flos Sanctorum by Alonso de Villegas or several "comedias de santos" by Lope de Vega) rescued the biographies of those "extravagant" saints, and with them all the echoes of a perfection based on the inversion of the appearances of knowledge. The study reviews the profiles of sacred stultice in these and other contemporary texts, as a preamble to a more ambitious exploration of the place that this hagiographic motif may have occupied in the discourse of the Counter-Reformation.

Keywords: Fools for the Christ. Hagiography. Counter-Reformation. Matthaeus Rader. Lope de Vega.

* La presente publicación se inscribe en el marco de los Proyectos de Investigación FFI2017-86248-

P y FFI2016-75396-P, y de los trabajos del Grupo de Investigación Clarisel. 


\section{LOCURA, HUMILDAD Y OBEDIENCIA}

L a figura del "loco (y del simple) de Cristo" posee una sólida presencia en la tradición hagiográfica de la Iglesia Oriental, aflorando de manera algo más discreta en los santorales de Occidente. El tópico asume modulaciones muy diversas, al hilo del diferente sesgo que adoptan los comportamientos de esos hombres -del arrebato y el desvarío a la ignorancia o la ingenuidad extrema- y, ante todo, de la exacta condición -real, fingida o meramente imputada por el entorno- de esa estulticia. La sola creencia en los misterios de la fe, en efecto, puede ser ya una forma de delirio a los ojos del mundo, como supo san Pablo, orgulloso de esa "locura por el amor de Cristo" (Mollat 63843; Saward 16-23). Pero es cierto que, en ocasiones, la verdad de Dios halla su asiento en el discurso de los ignorantes, convertidos en depositarios de una sabiduría sagrada, que desafía la ciencia de los doctos. En muchos otros casos, por último, el arrebato es el fruto de la simulación, de la teatralización de una demencia extravagante en el gesto y en las palabras, capaz de desvelar de nuevo, desde la paradoja o desde la risa, la falsedad de la sabiduría mundana.

Bajo cualquiera de esos perfiles discurre por las letras cristianas una sagrada estulticia émula de aquella enajenación de los viejos profetas, afecta a la contemplación del Jesús de la Pasión (presentado por sus verdugos con todos los atributos de un loco o un rey de farsa) y autorizada por aquellas reflexiones paulinas sobre la "locura de la Cruz" y por otras citas del Testamento Viejo y del Nuevo (Mollat 636-38; 643-44). La locura o la simplicidad sagrada, supuesta, real o simulada, se encarna así en aquellos monjes y solitarios bizantinos (la monja Isidora, Simeón de Emesa, Marcos de Alejandría, Andrés de Constantinopla) tildados de "locos" o "idiotas" (saloi). Y esa misma condición anida en los "locos por Cristo" (yurodivye) que deambulan por las ciudades de la antigua Rusia, como Procopio de Ustiug, Isidoro de Rostov, Basilio de Moscú y Nicolás de Pskov (Špidlík 757-60; Ivanov). En Occidente, la sagrada estulticia adopta un perfil más difuso, según decíamos, y acaso más moderado. Algunos de los signos de ese curioso estigma asoman ya en los "hombres salvajes" (gelta) de la primitiva Irlanda, en el siglo VII, cobrando un aire festivo en algunos eremitas del siglo XI, como san Romualdo, o en los primeros cartujos. Todos ellos supieron teñir sus palabras de alegría, haciendo suya la misión de proclamar el "Evangelio del buen humor". Y esa misma misión compartieron, de modo todavía más decidido, los "bufones de Dios" cistercienses, equiparados al niño, al indigente, al idiota, para llevar a un extremo el espíritu de Bernardo de Claraval, quien no dudó en presentarse como juglar (joculator) o 
como acróbata (saltator). "Locos del mundo" (moriones mundi) y juglares fueron también los franciscanos, desde fray Junípero a Jacopone de Todi, por voluntad de su fundador, cuyo pensamiento aparece delineado sobre varios de los principios que vertebran esa concepción de la santidad (la preferencia por la alegría y la risa, la hermandad con los marginados, la identificación con el Cristo vilipendiado en la Pasión). El siglo XIII constituye así el inicio de una "edad de oro" de la locura sagrada consolidada en las dos centurias siguientes, y prolongada en el Quinientos gracias a la labor de un puñado de hombres insignes: Ignacio de Loyola, quien impuso a la Compañía en sus Ejercicios y en sus Constituciones la necesaria imitación del Cristo escarnecido y el consiguiente deseo de "ser tenidos y estimados por locos" (aunque, eso sí, "no dando [...] occasión alguna dello"); ${ }^{1}$ Felipe Neri, paradigma del gusto por la broma y la festività; Tomás Moro, que mantuvo su espíritu jovial hasta el momento de su ejecución y a quien el mismo Erasmo había dedicado su Elogio de la locura, obra en la que tampoco falta la oposición entre la locura de Cristo -verdadera sabiduría del Padre- y la vanidad del cristianismo de su tiempo.

El aprecio por los simples de Cristo pervivirá más allá del siglo XVI, pero la locura sagrada será percibida paulatinamente de un modo más conflictivo, dadas las crecientes prevenciones del entorno social -y su propia hostilidadhacia la insania mental. El santo loco vivirá finalmente su experiencia en los márgenes de esa sociedad, a diferencia de sus predecesores medievales y renacentistas, cuya soledad, en caso de existir, no nacía tanto de su aislamiento del mundo, cuanto de su presencia, interrogante y benefactora, en el seno de un entorno admirado y expectante (Saward 51-148; Vandenbroucke). ${ }^{2}$ En este sentido, es verdad que la indudable curiosidad científica y artística despertada por el tema general de la demencia desde los inicios del Barroco hubo de renovar el interés por aquellos arrebatados santos del pasado: pero es igualmente obvio que aquellas viejas historias hubieron de comenzar a leerse ya con una cierta dosis de extrañeza, o acaso de nostalgia.

1. Constituciones 4, 101 (Ignacio de Loyola 486); también Ejercicios espirituales 167 (131).

2. Para una primera aproximación al tema, a los panoramas de Saward e Ivanov y los trabajos de Mollat, Špidlík y Vandenbroucke citados, deberían sumarse, al menos, la entrada de Derville y los estudios de Redondo, Feuerstein y Michel de Certeau (39-56), quien analiza la figura del loco en el cristianismo antiguo como antecedente del místico. Para la percepción social de la locura en el siglo XVII es imprescindible el espléndido trabajo de Foucault. Para la Edad Media y el Renacimiento, sigue siendo útil el estudio de Swain. Para la fortuna general del tema de la locura en las letras áureas castellanas, Bigeard, los artículos reunidos por Redondo y Rochon, y los trabajos de Márquez Villanueva (1979; 1985-1986). 
No es preciso, por lo demás, insistir aquí en la osadía de la conducta del loco sagrado, en lo que la misma tiene de desafío y de contestación a las normas. Y, sin embargo, la biografía de la mayor parte de esos hombres venerables se asienta, con una convicción no menor, en los pilares de la humildad -o, por mejor decir, de la humillación propia- y de la obediencia. Es cierto que una libertad aparentemente escandalosa preside los actos de algunos saloi bizantinos y de la mayor parte de los yurodivye rusos. Como lo es que estos últimos hacen gala, en ocasiones, de un evidente anticlericalismo. Pero, al menos en la tradición occidental, los locos (y todavía en mayor medida los simples sagrados) hicieron de la obediencia extrema uno de los signos de su existencia: obediencia al abad y a todos y cada uno de los miembros de la comunidad, obediencia ciega a Dios. A pesar de su condición excéntrica, la sagrada estulticia posee en Occidente un carácter "profundamente eclesial y católico". La del santo loco es una anima ecclesiastica, que practica una sumisión total a la Esposa de Cristo, en oposición al hereje y al cismático, quienes, caracterizados por su falta de abnegación, "prefieren sus opiniones personales (o la sabiduría del mundo) a la verdad revelada en su plenitud, renunciando así a la locura de la Cruz" (Saward 10).

A esa luz, es posible que la presencia del tema de la "sagrada estulticia" en algunos textos redactados en la frontera entre los siglos XVI y XVII posea un sentido algo más complejo que el dictado por la propia extravagancia -teñida de anacronismo, según decíamos- de su asunto, o por la citada curiosidad que el tema de la locura, en todas sus manifestaciones, despertó en la época. Quiero decir que, de un modo u otro, el recuerdo de ese tema en la Contrarreforma rescataba los ecos de una perfección cristiana cimentada en algunos de los principios que sostenían la defensa coetánea de la fe católica: la humildad extrema, la sumisión a la autoridad eclesiástica y, por qué no, la gustosa aceptación de los misterios más profundos de la fe. Quién sabe si, por ello, las reticencias y prevenciones ante ciertas manifestaciones de la santa locura, crecientes en todo Occidente, pudieron ser algo más suaves en la orilla católica que en la protestante, donde el calvinismo, como recuerda Saward (143-47), se mostró especialmente crítico con esa vieja tolerancia hacia la presencia de la risa y la amentia en el ámbito sagrado.

Es asunto -el de la posible dimensión polemista del tema en la Contrarreforma- que desborda el interés de estas páginas, interesadas únicamente en el repaso de un puñado de títulos que, en nuestras letras, contribuyeron al recuerdo de las encarnaciones más antiguas y más recientes de la santa estulti- 
cia. Según se verá, unas y otras hallan su cobijo en las páginas de nuestros santorales postridentinos, y se convierten en asunto -central o meramente episódico- de un número nada desdeñable de comedias de santos barrocas, varias de ellas escritas por Lope o a él atribuidas. Aunque quizá no esté de más recordar que, por esas mismas fechas, las letras latinas habían proporcionado ya en una sola obra -el De simplici obedientia, del jesuita Matthaeus Rader (15611634) - el más amplio catálogo de ejemplos de la sagrada locura y las más atinadas reflexiones acerca de sus formas y de su sentido.

\section{MatTHaeus Rader y LA “SIMPLE ObEDIENCIA”}

No existe, seguramente, un texto más interesante -y más desatendido- en torno a la estulticia sagrada que el tratado sobre "la simple obediencia y el desprecio de sí mismo" de Rader (o Radero, como lo conocieron las letras españolas), convenientemente adornado con un apéndice de "dichos y hechos de algunos simples" (De simplici obedientia et contemptu sui cum auctario de quorundam simplicium dictis et factis, ex latinis, italicis, graecis delibata, conscripta et recognita). ${ }^{3}$ El tratado fue concebido desde su inicio como segunda parte del Viridarium Sanctorum del autor, obra que ofrecía en su entrega inicial, de 1604, una selección de vidas de santos orientales traducidas de la Menaea (el breviario de la Iglesia Ortodoxa Griega). El De simplici obedientia vio la luz por vez primera en Augsburgo, en 1610. En 1614 fue publicado entre los Opuscula sacra del autor preparados en Munich, donde figuraba entre aquella entrega inicial de vidas de santos orientales y una tercera sección, de carácter misceláneo, conformando el llamado Viridarium Sanctorum Tripartitum. Un texto este último que, como obra exenta, conocería una segunda edición en Lyon, en las prensas de Michel Chevalier, en 1627.

El De simplici obedientia de Rader es un texto singular, acaso inaudito. Es verdad que la consideración de la "sancta simplicitas" no es en modo alguno ajena a la historia de las letras cristianas. Ese rótulo amparaba, por ejemplo,

3. De la figura de Rader se ocupan Lukas y Schmid. Pedagogo, filólogo y erudito, ingresó en los jesuitas en 1581 y fue profesor de Retórica en los colegios de la Compañía en Augsburgo y Munich. A él se deben, amén de varias obras de uso escolar, la biografía del también jesuita Pedro Canisio, una amplia colección de vidas de santos bávaros, un conocido comentario sobre Marcial, que publicó precedido de una edición de su obra, un segundo comento sobre la Historia Alexandri Magni de Quinto Curcio y diversas incursiones en el ámbito de los estudios bizantinos (así, la traducción de las obras de Juan Clímaco), al que remiten, en definitiva, buena parte de los contenidos del tratado De simplici obedientia. 
uno de los capítulos de la segunda biografía de san Francisco debida a Celano y servía de título a un curioso opúsculo de Pedro Damián (De sancta simplicitate scientiae inflanti anteponenda),${ }^{4}$ trufado con el recuerdo de unos cuantos ilustres ignorantes: Benito, Antonio, Hilarión. De modo más específico, el célebre Dialogus miraculorum (ca. 1219-1223) de Cesáreo de Heisterbach había consagrado su amplísima "distinctio sexta" a la "simplicitas", rúbrica presente en otras colecciones de "exempla" medievales. Pero a duras penas podría sentirse ese texto de Heisterbach como un pálido antecedente de la obra de Rader, distanciada no solo por su mayor extensión o por la propia diversidad de las historias recogidas, sino, quizá ante todo, por su voluntad de ofrecer un itinerario sistemático y pleno de reflexiones teóricas por los espacios de la estulticia sagrada y por sus paisajes aledaños: los de la obediencia y los de una humildad identificada, según decíamos, con el menosprecio de sí mismo.

El tratado se halla inaugurado en sus dos primeras ediciones por una cita del Libro de la Sabiduría en torno a aquellos "santos e hijos de Dios" tenidos por locos y sometidos a la burla y el escarnio (Sb 5, 3-5), inequívoca al propósito de la intención central de sus páginas. Rader, en cualquier caso, destina el primer capítulo de la obra a ofrecer una reflexión preliminar sobre los beneficios generales de la obediencia ("De simplici studio obsequendi in vulgo paradoxis", 1-20). Hasta las bestias más salvajes -osos, leones, tigres, ballenas- se habían mostrado ocasionalmente sumisas a la voz de los hombres, según recordaba el jesuita, antes de exponer una galería de casos en los que Dios había ordenado a los suyos acometer acciones inusitadas. Una galería inaugurada por el ejemplo de los profetas (Isaías, desnudo y descalzo; Jeremías con el yugo y las coyundas en su cuello; Ezequiel, arrojando al aire y al fuego su cabello; Oseas tomando mujer del prostíbulo) y pronto oscilada hacia los simples del yermo: como Paulo el Simple, detenido día y noche a las puertas de la ermita de san Antonio, o Juan, empeñado en regar durante un año dos veces al día un palo seco por orden de su abad. La "sencillez obediente" del primero contaba con más elogios que la misma sabiduría de Aristóteles, recordaba Rader, que aducía el testimonio de las Vitae Patrum atribuidas a san Jerónimo, la Lausiaca de Paladio, los textos de Sozomeno y de Nicéforo o la Scala Paradisi de Juan Clímaco. Un puñado de textos cuyo solo recuerdo imponía ya una guía mínima para adentrarse en esos espacios de la locura sagrada que prometía explorar el De simplici obedientia.

4. Para el opúsculo de Pedro Damián, Vandenbroucke 765. 
El segundo capítulo del tratado irá cercando ese propósito, sin llegar todavía a abordarlo, al proponer un singular listado de casos de sumisión "llevada hasta la muerte" "De simplici obediencia sanctorum usque ad necem", 2135). El listado se inicia con el recuerdo de la historia de Abraham e Isaac, sentida como "signum et symbolum" de la aceptación de la muerte en la cruz por parte de Cristo, para desplazarse de nuevo, de modo inevitable, hacia el yermo oriental, en busca de algunos émulos de esa ciega obediencia, como Mucio, dispuesto a arrojar al río a su propio hijo siguiendo una falsa orden de su abad, Juan, enviado por el suyo a atrapar una fiera salvaje, o aquel otro monje que, acatando el mandato de su hermano, no dudó en introducirse en un río lleno de cocodrilos.

Los dos capítulos iniciales del De simplici obedientia insinúan así los perfiles de esa sagrada estulticia abordada con resolución en su extensísimo tercer capítulo ("Sancti qui simplicitatem \& fatuitatem ob sui contemptum finxere", 36-135). De hecho, este último se abría con un oportuno preámbulo sobre el concepto de "simplicitas", acompañado de una curiosa tipología de los "simples” y de una cautelosa reflexión sobre las posibilidades de su imitación. Tras un cumplido elogio de la simplicidad (cualidad del mismo Dios, "a quien nada se puede añadir ni restar”), Rader anudaba citas paganas y cristianas para identificar esta última con la pureza y la integridad, con la sinceridad incorruptible ("intemerata sinceritas"), ajena a cualquier pensamiento perverso. Siguiendo el discurso de Juan Clímaco, Rader distinguía dos tipos de simplicidad: la innata (como la de Adán antes del pecado o la de los niños, llamada "inocencia") y la adquirida ("quaesita"), es decir, la procurada con esfuerzo y llevada, gracias a la obediencia, hacia un "sincero candor espiritual". Es por esa vía por la que, en nombre de Cristo, podía llegarse a una "cauta simulación de fatuidad", bien entendida, claro está, y alejada de los riesgos de la hipocresía. La historia civil y religiosa se mostraba, al decir de Rader, llena de hombres ilustres que fingieron "no ya simplicidad, sino estulticia y locura" por un buen fin (David, Solón, Sócrates, Ulises), como lo hicieron algunos "santos nuestros": Siméon el Loco, Isidora, Jacopone de Todi...

Rader dedicará todavía algunas páginas más a cimentar esa "ética de la simulación" antes de introducir la segunda de sus reflexiones teóricas: una preciosa tipología de los "santos que practicaron la simplicidad". En primer lugar, señala el jesuita, están aquellos que dicen de inmediato lo que piensan, que, como niños, no saben mentir ni simular, que no tienen la miel en la boca, sino en el corazón; aquellos que, tenidos por insensatos, estúpidos, tontos, son ob- 
jeto de la burla de los demás ("pro fatuis, stupidis, hebetibus, blennis, bardis, stultis denique habentur, ridentur, exploduntur"). Un segundo grupo es el representado por cuantos adquirieron ese galardón de simples gracias a la obediencia, al modo de Abraham o de aquel Mucio ya aludido en el capítulo anterior. El tercer género acoge a quienes "no piensan en venganza cuando son lastimados [...] se alegran cuando se burlan de ellos [...] y no pagan el mal con mal", deseando ser tenidos por tontos y ser así llamados ("pro fatuis, fungis, bardis, haberi, dici, tractarique cupiunt"). El siguiente grado corresponde a los que han alcanzado tal perfección que "más se ríen del vulgo que el vulgo de ellos", ambicionando el desprecio tanto como otros mueren por los honores, deseando la pobreza como otros ambicionan la riqueza, y siendo atraídos por las mujeres no más que por una piedra o un tronco; aunque por doquier llaman a todos ellos fatuos y, a la mayor parte, locos ("limphati, cerriti, furiosi, plurimi ipsis"). El quinto género es el de los en verdad simples de ingenio; quienes, como Paulo el Simple, conservaron su ingenuidad y aun la aumentaron gracias al ingreso en religión. El sexto tipo, por fin, define simplemente a aquellos mártires "juzgados por ignorantes y dementes por los paganos", solo porque no quisieron esconder su amor a Cristo.

El preámbulo teórico de Rader se completa con una enésima reflexión acerca de la distancia entre la hipocresía y la simulación sagrada de la locura: "fingir estar loco sin una causa santa es locura [...] portarse como un idiota para provocar la risa [...] es estulticia [...] Fingirse en un momento dado loco, arrebatado, necio o ingenuo, por un impulso divino [...] o por reprimir la vanagloria, no solo es digno de admiración y de elogio, sino también de imitación". Tan solo tras esa cautelosa advertencia había de hallar el lector la pertinente retahíla de historias de "locos simulados", iniciada por la del rey David, y continuada con las de un elenco nada desdeñable de santos antiguos: Indes y Domna, quien se fingió loca ante sus perseguidores paganos, la ya citada monja Isidora, quien servía la comida a sus compañeras en el convento y comía a solas sus migajas, deseando ser tomada por idiota, los "fatui" Marcos de Alejandría y Simeón de Emesa... Un elenco, en cualquier caso, prolongado con algunas figuras acaso más próximas, como Cristina "la Admirable", encerrada por sus allegados como una posesa, san Francisco, sometido por voluntad propia a la burla pública, su discípulo fray Junípero, estúpido solo a los ojos de los estúpidos de este mundo, el también franciscano Jacopone de Todi, cuya vida de penitencia ofrecía todo un enhebrado de secuencias hilarantes y escandalosas, tejidas sobre los motivos de la desnudez y el disfraz carnavalesco, 
el jesuita Gonzalo Silveria, “máximo despreciador de sí mismo”, o Juan Leonardo Geruso de Santa Severina, de cuyos hechos nada sabía Rader, más allá de lo dicho al pie de una estampa que llegó a sus manos: que fingía su demencia, y que se dedicó a socorrer a los niños pobres hasta su reciente muerte, en 1595, en Roma.

El discurso de Rader oscilará en el siguiente capítulo -el cuarto del tratado- para explorar los visos de la locura meramente imputada ("Qui nulla sua culpa pro simplicibus, fatuis insanis habiti, in ipso contemptu sui triumpharunt”, 136-58). El apartado concilia el recuerdo de Sócrates con el de Job y Sansón, reservando un espacio central a Cristo, quien fue "tenido, a causa de la estupidez de los hombres, por un loco, un demente, un charlatán, fue sometido a la risa y a la burla, y fue escupido, y traído y llevado a puñetazos, recibiendo mil ultrajes y vejaciones solo por diversión". Es esa imagen del Cristo escarnecido en la Pasión la que guiaba la vida de los miembros de la Compañía de Jesús, según impuso San Ignacio en sus Constituciones, en un pasaje oportunamente transcrito por Rader, y la que había orientado los propios actos del fundador, como habían mostrado sus hagiógrafos, Ribadeneyra y Maffei, cuyas palabras también habían de ser recordadas en el capítulo. Las páginas de este último, por lo demás, se completarían con unos cuantos casos de santos vilipendiados: los propios apóstoles (evocados al amparo de una cita paulina especialmente grata a todos los discursos sobre la locura cristiana: I Cor 4), un porquero anacoreta o san Eduardo, rey de los ingleses, entre otros.

El penúltimo capítulo del opúsculo (159-89) ofrece aquel apéndice prometido desde su portada, bajo el rótulo, levemente modificado, de "Mantissa de simplicium quorundam dictis factisque" (es decir, "Suplemento de dichos y hechos de ciertos simples"). Es posible que el apartado tan solo pretendiera dar cobijo a algunos materiales que no encontraban acomodo en las páginas precedentes de la obra. Pero es verdad que su mismo título lo emparentaba, de modo consciente, con todas aquellas colecciones de "dicta et facta memorabilia" que, al amparo del modelo fijado por Valerio Máximo, había prodigado el Humanismo (las compilaciones de Fulgosio y de Sabelico, o la más decididamente religiosa de Marulic); como lo es que sus páginas parecían hacer suyos aquellos principios que habían garantizado el éxito de estas últimas obras (y de algún género afín, como el de los ejemplarios homiléticos tardomedievales) en las prensas renacentistas y barrocas: también la "Mantissa" de Rader parecía aunar, en efecto, la búsqueda de una lección moral con el gusto por el prodigio y la maravilla. Ejemplario mínimo y silva de varia lección, el 
apéndice abordaba el caso de los simples que decidieron castrarse por Cristo, para referir a continuación tres deliciosos ejemplos de imágenes del niño Jesús alimentadas por niños (Hermann de Colonia, los discípulos del dominico portugués Bernardo y un tercer "puer religiosus" anónimo), a los que se sumaban algunas historias de tema mariano, como la de Salauno, capaz tan solo de aprender las dos primeras palabras de la oración del "Ave María", o la de aquel monje atormentado, dispuesto a acusar a Cristo ante la Virgen si no era liberado de su mal. Era ejemplo este último tomado del citado Dialogus miraculorum de Heisterbach, obra a la que Rader remitía a aquellos lectores interesados en casos semejantes, pero de la que prudentemente se distanciaba, porque no estaba en su ánimo reunir los delirios (“errores”) de los más simples, sino -reiteraba una vez más- escribir acerca "de los justos que simularon simplicidad por una intención piadosa, o ascendieron hacia la perfección cristiana por su candor natural, o sufrieron pacientemente los perversos ataques de otros".

A esa luz, no es extraño que el De simplici obedientia no se cierre con ese apéndice de "ejemplos" curiosos. Para disipar cualquier duda, Rader había de añadir un sexto y último capítulo, detenido en el modelo omnipresente de todas sus páginas -el de Cristo, claro está- y en un tema capital en ellas: el de la humildad. Concebido como epílogo, el capítulo "De humilitate Christi" (190207) desgranaba el sentido de esos "ejemplos de modestia y sumisión" del Hijo de Dios en la tierra, y su condición de "norma de vida" para el cristiano. Todo ello a través de un discurso trufado de razones y "exempla", que había de dar paso a un poema final, rematado por un lema bíblico ("Qui se humiliat, exaltabitur", $L c 14,11$ ) de enorme fortuna en las letras cristianas. Con esa apelación a la humildad, el tratado de Rader cerraba un círculo abierto con el elogio de la obediencia de su primer capítulo, otorgando un marco -y un sentido trascendente- a ese cumplido itinerario por los espacios de la ingenuidad, la locura y la maravilla que imbricaba la obra.

\section{PRADOS Y FLORES DE LA ESTULTICIA}

A la altura de 1610, el De simplici obedientia de Rader no podía ocultar la lejanía (histórica y acaso también geográfica) de una vivencia de la "simplicitas" vinculada a los viejos cenobios medievales y sin duda más arraigada en el yermo oriental. El tratado transparentaba, de hecho, una indudable concesión a la curiosidad, incluso a la rareza (prolongada en la tercera entrega del Virida- 
rium, que reservaba un espacio a los santos ciegos y a los estilitas). No parece necesario insistir aquí en la oportunidad de la escritura de ese tratado poblado por santos dementes y monjes simples, a tenor de la mencionada fascinación barroca por todas las manifestaciones de la locura. Y, sin embargo, si un valor tiene la obra es el de establecer, acaso por vez primera, un marco teórico para el análisis de la estulticia sagrada. La lectura del De simplici obedientia se revela como un punto de partida ideal para una comprensión cabal de ese tema hagiográfico, como el análisis de su influjo -en la escritura y en las vivencias religiosas de sus lectores- constituye una labor inexcusable a la hora de valorar la pervivencia de esa forma extrema de la santidad en el Barroco.

No conocemos cuál pudo ser la recepción del texto de Rader en el ámbito hispánico. Aunque es cierto que no faltan ejemplares de su Viridarium en las bibliotecas peninsulares, y que buena parte de los episodios abordados en ese tratado circularon abundantemente en la época en aquellas versiones que habían servido de fuente a su autor. Las Vitae Patrum atribuidas a san Jerónimo gozaron de una difusión notable en su versión latina, y también en la traducción elaborada a finales del XV por Gonzalo García de Santa María (Las vidas de los sanctos religiosos de Egipto), impresa con asiduidad hasta mediados del Quinientos (Mateo Palacios 49-62). La obra latina cobró una nueva actualidad en 1615, gracias a la excelente edición del jesuita Heribert Rosweyde, cuyas magnas Vitae Patrum aunaban los contenidos atribuidos a san Jerónimo con los de algunas otras obras afines: entre otras, la citada Lausiaca de Paladio y el Pratum Spirituale de Juan Mosco. Son textos -junto a la Scala Paradisi de Juan Clímaco- bien conocidos en el periodo y que disfrutaron, en algún caso, de una rica herencia en nuestras letras. La Scala Paradisi contó al menos con dos traducciones al castellano anteriores a la publicada en 1562, nacida justamente para superar las dificultades de aquellas: que "la una es [...] tan antigua, que apenas se entiende, y la otra [...] hecha por un aragonés o valenciano [...] no es menos escura y difícil [...] así por la dificultad del libro como por muchos vocablos que tiene peregrinos y estranjeros, como son bahorrina, soledumbre, inrobable, y otros tales" (Juan Clímaco, s.f.). Poco más tarde, Juan Basilio Sanctoro daría a la luz su Prado Espiritual (1578), obra que incluía una traducción del Pratum de Juan Mosco (que allí se atribuía todavía a Sofronio) y otros materiales tomados de fuentes diversas (Sulpicio Severo, Juan Casiano, Paladio, Teodoreto, Simeón Metafraste, Gregorio de Tours, Enrique Gran, Juan Clímaco, Cesáreo de Heisterbach y el Liber de apibus, entre otros). Beneficiada por un notable éxito editorial, la obra de Sanctoro ofrece alguna muestra de la 
presencia de la sagrada estulticia en nuestras letras: por allí asoman, por ejemplo, la historia del abad Moisés, "que procuró que le tuviesen por loco" (6768), y una enésima versión de la vida de la monja Isidora (128-29).5

Esa presencia, claro está, puede rastrearse también en los santorales al alcance de los lectores hispánicos. Quizá no tanto en los más añejos, como la Legenda aurea latina de Varazze y sus derivados castellanos, medievales y renacentistas, pero sí, sin duda, en los legendarios postridentinos que hubieron de sustituir a aquellos. Las Vitae Sanctorum latinas de Lipomano y Surio, publicadas en seis volúmenes, entre 1570 y 1577 , dieron cobijo a un elenco ingente de hagiografías, entre las que habían de encontrarse, por fuerza, algunas de las que adornaban el panteón de la sagrada estulticia. Allí figuran la historia de Domna e Indes (IV, 2-22) o la de Simeón Abad, “cognominatus salus, id est, stultus" (vI, 998-1010). Aunque es verdad que, en la obra, la voz "amentia" asoma ante todo por los relatos martiriales, empleada para calificar la furia de los perseguidores o utilizada por estos últimos para definir la fe de los cristianos y su firme disposición a morir por Cristo. Son voces y motivos heredados por aquellos dos legendarios castellanos que, basados parcialmente en la obra de Lipomano y Surio, inundaron las prensas postridentinas: el Flos Sanctorum de Alonso de Villegas, distribuido en seis volúmenes (15781604), y el santoral homónimo de Pedro de Ribadeneyra, publicado en tres entregas (1599-1604).

Es seguramente en el legendario de Villegas donde el tema de la santa locura cobra un relieve más acusado. Lo hace ya en su primer tomo, donde, al hilo de la Fiesta de la Cátedra de San Pedro, el maestro toledano recordará que el Apóstol fue tildado de "loco" por parte de Teófilo, gobernador de Antioquía, quien "le mandó cortar el cabello de la cabeza en medio, dejándole un pequeño borde a la redonda, a manera de corona [...] por irrisión" (90v-91r). Algo después, Villegas hermanará las figuras de san Francisco y David, haciendo de este "sombra y figura" de aquel; que si el Rey Profeta "se fingió loco furioso" para librarse del filisteo Aquis, también Francisco supo "hacer muchas de loco al parecer del mundo" (241v-242r). El ejemplo de David es evocado de nuevo en el segundo tomo de ese Flos Sanctorum (192r), dedicado a ex-

5. En su primera edición zaragozana, en 1578 , y en la burgalesa de 1588, la obra aparecía distribuida en tres libros, los dos últimos con materiales ajenos a Juan Mosco. En 1592 vio la luz en Burgos la segunda parte, formada por otros tres libros. La obra contó con una decena de ediciones entre aquella primera de 1578 y la última conocida, en Madrid, en 1674. 
poner la Vida de la Virgen y la de "los santos antiguos, que fueron antes de la venida de nuestro Salvador". Por allí asoman también las burlas que hubo de soportar Noé ("Sal, viejo loco, ¿a qué te has enjaulado con tantas bestias?"), en un episodio que permite a Villegas deslizarse hacia el tema de la locura imputada a los justos, rememorando las palabras de san Pablo ("por amor de Cristo somos tenidos por locos") y aquel mismo pasaje del Libro de la Sabiduría que inauguraba la obra de Matthaeus Rader: "Pensábamos que su vida era locura y hallamos que nosotros somos los locos" (98v-99r). De hecho, no faltan en el texto castellano algunas muestras de esa obediente simplicidad explorada por el jesuita alemán: también el Flos Sanctorum recordaba la historia de aquel monje Juan, "a quien su abad para prueba de su obediencia le mandó que regase dos veces al día un palo", y la de Mucio, a punto de cumplir la orden de arrojar a su propio hijo al agua (189r-v).

Será, con todo, en el tercer tomo del Flos Sanctorum, dedicado a los "santos extravagantes” (es decir, a los no contemplados en el Breviario Romano), donde Villegas muestre un mayor interés por el asunto. Allí se incluye, por ejemplo, la Vida de "fray Jacopono de Tode" (21r-22r), nombre puesto "por irrisión [...] llamándose él Jacobo, como si en español al que se llama Diego, por menosprecio y mofa le llamasen Diegón”. En el relato se da cuenta de su dedicación inicial a la abogacía, de la accidentada muerte de su virtuosa mujer y del descubrimiento del cilicio que esta última traía bajo sus vestidos, motivo de la radical conversión del esposo. Jacopone, en efecto, procuró desde ese momento "seguir el camino de la humildad", distribuyendo sus riquezas, vistiendo un hábito pobre y, ante todo, haciendo "cosas de loco", que movían "a unos a risa, y a otros a lágrimas". Villegas no dudará en interrumpir la narración de esa curiosa hagiografía para introducir una reflexión moral acerca de aquellas "cosas que se hallan en la Escritura Sagrada que hicieron los santos, que en los ojos de gente mundana eran locura y desatino, y en los de Dios [...] eran sabiduría grande", evocando de nuevo el ejemplo de David, junto al de Oseas, y aconsejando, en la línea del propio Rader, que nadie, "guiado de su propio parecer, presuma hacer cosas semejantes". Solo tras esa advertencia retomaría el recuento de las extravagancias del penitente. Como aquella acaecida en las fiestas generales de la ciudad, cuando se desnudó "su vestido hasta la cinta" y se puso "a las espaldas la albarda de un jumento, y andando con los pies y con las manos a la manera de bestia, salió entre la gente". O la que tuvo lugar cuando un hermano suyo se disponía a casarse, y envió a un pariente para que rogara a fray Jacopono que "no le deshonrase con algu- 
na locura ese día"; algo que, por supuesto, no evitó que él "hiciese una de las suyas, y fue que se desnudó y untó todo de pies a cabeza con trementina, y revolcose entre plumas de diversos colores que sacó de un cabezal, y todo cubierto de ellas y muy emplumado, entró en casa del hermano en medio de las danzas y fiestas [...] dejando a los circunstantes llenos de asombro y tristeza". La biografía de Jacopone de Todi es paradigmática a propósito de todos los tópicos que la tradición sedimentó sobre la figura del "loco sagrado". Pero lo es quizá ante todo por esa tensión entre la burla y la compunción (tan cercana a la penitencia) que provocan sus actos, y por la agudeza que se revela tras su aparente locura. La suya no es, por lo demás, la única aparición de la locura sagrada en el tomo de "extravagantes". También Gangulfo, al querer comprar una fuente "para pasarla a su tierra", fue tomado por "hombre loco y sin juicio" por el vendedor y por su misma esposa, que ignoraban el poder de la fe (213r); como lo fue san Estanislao, al ofrecerse a traer como testigo en una disputa al hombre que le había vendido una heredad, muerto ya hacía tres años $(257 \mathrm{v})$. El volumen ofrece un adecuado espacio, además, a la Vida de Tomás Moro (Adición, 66r-68r), que "gustaba de oír y decir dichos agudos y graciosos”, y, sobre todo, a dos historias con una mayor fortuna en nuestras letras: la de "San Indes, y Domna, con los veinte mil mártires de Nicomedia" (42v-46r) y la de san Juan de Dios (Adición, 69r-72v).

La cuarta de las entregas del Flos Sanctorum de Villegas constituye, en lo esencial, una recopilación de sermones, por donde asoman de nuevo los ejemplos de David y san Juan Bautista (195v, 370r), como lo hacen las burlas a Cristo, evocadas en varias de las piezas del conjunto (43r, 85r, 188v, 447r, 481r) y convertidas en asunto medular de los discursos LXI ("De la corona de espinas, para el Sábado Santo", 195v-197v) y CXLVIII ("De Todos Sanctos", 435r-437v). En aquel, el maestro toledano celebra la voluntad de Cristo "de haber sido tenido, al talle de David, por loco, por rey de burla", rememorando la imagen de su coronación, "donde se juntaron burlas y veras". Y esa misma imagen aparece en el segundo discurso, bendiciendo al Cristo al que "los sayones y verdugos [...] tuvieron por loco", al que "daban pescozadas, remesones y palos, poniéndole corona de burla y cetro de mofa, y ropa de escarnio"; aquel, en fin, al que "los escribas y fariseos, teniéndole en la cruz, le juzgaban por la misma locura".

Un interés no menor ofrece la quinta entrega del santoral, acogida bajo el nombre de Fructus Sanctorum y concebida como una suma de "exempla" organizados en torno a setenta y ocho capítulos temáticos. Por sus páginas 
afloran de nuevo la demencia simulada de David (34v) o el episodio de locura de san Juan de Dios (327r-v), ejemplos a los que se suma al menos uno pagano (el de Diógenes, "tenido de los mochachos por loco, y perseguido de ellos", 474v), que la vocación miscelánea del conjunto invitaba a acoger. Es, en efecto, esa variedad temática de la que hacían gala los ejemplarios cristianos la que convirtió el género, desde el medioevo, en un marco adecuado para la transmisión de la estulticia sagrada. El Magnum Speculum Exemplorum (redactado hacia 1480, y revisado en los inicios del XVII para su difusión en las prensas) incluye bajo la rúbrica de la "simplicitas" un solo caso, también presente en la obra de Rader: aquel de Salauno, "mendigo pobre, rudo y simple que, enviado a la escuela en sus años de infancia, nada pudo aprender más allá de las palabras latinas Ave Maria", y sobre cuyo lecho de muerte floreció milagrosamente un "lilium pulcherrimum", cuyas flores mostraban aquellas dos mismas palabras, escritas con letras doradas (730). El Fasciculum Exemplorum de Ioannes Faius, otro ejemplario medieval rescatado por la imprenta barroca, recogía también una sola anécdota bajo la misma rúbrica: la de un ingenuo monje, enviado por el abad a recuperar el ganado usurpado al convento por un noble, y sentado a la mesa de este último para traer en su estómago algo de esa carne robada, obedeciendo así al pie de la letra las órdenes de su superior (395). Es ejemplo, este último, presente al inicio de la citada "distinción sexta" del Dialogus miraculorum de Cesáreo de Heisterbach, obra que también gozó de una evidente fortuna editorial en la frontera entre los siglos XVI y XVII. La "distinción sexta” (396-452), precedida por una reflexión moral sobre la "simplicidad" (virtud "que no conoce la hiel [...] ni el rencor"), constaba de un total de treinta y seis "exempla". No todos ellos responden de modo estricto a esa idea de ingenuidad que proclamaba aquella reflexión preliminar: también hay algunos casos conducidos "ex contrario", historias de soberbia y engaño, de ambición y de astucia. Pero acaso sea justamente en ese contexto -en el de esa variada galería de anécdotas, entre las que no falta el recurso a la violencia y a la muerte, a la risa y a la maravilla- donde la sagrada estulticia revela todo su potencial "literario". Aquel que hubo de convertirla, por ejemplo, en asunto central de un conjunto nada desdeñable de comedias áureas. ${ }^{6}$

6. No es ni por asomo este el único indicio de la influencia del tema de la estulticia sagrada en nuestras letras. Para la proyección de la figura del Cristo de la Pasión sobre el personaje de don Quijote, por ejemplo, véase Gómez Moreno (2008; 2015). 


\section{TEATROS DE LA LOCURA}

Por supuesto, no es cuestión de analizar en estas páginas el lugar que la estulticia sagrada pudo desempeñar en la configuración de los temas y argumentos de un género tan fecundo como la comedia de santos. Pero quizá sí sea posible espigar en la obra lopesca algunas muestras de la presencia de ese tema hagiográfico, y de su imbricación allí con el elogio de aquellas dos virtudes que, según decíamos, lo sustentan: la humildad y la obediencia. De hecho, el encarecimiento de la primera es motivo recurrente en las comedias del Fénix, al punto de constituir el asunto medular de una pieza de tema profano, a la que otorga su título: La humildad y la soberbia o, como prefieren los dos últimos actos, La bumildad ensalzada. Este último rótulo recrea un conocido versículo evangélico, ya citado ("Quia omnis, qui se exaltat, humiliabitur: et qui se humiliat, exaltabitur”, Lc 14,11), traducido por Lope y reiterado en el texto al modo de un "aforismo o aviso moral", erigido en auténtico leitmotiv de la pieza, como observó Zugasti en su edición (487): "Dios ensalza al que se humilla / Dios humilla al que se ensalza". Con ligeras variantes, el aforismo aparece en diversos dramas de tema sagrado, como La hermosa Ester ("Dios ensalza los humildes / y derriba los soberbios", vv. 2391-92 y 2433-34) o fuan de Dios y Antón Martín, donde la cita evangélica se constituye en una suerte de "tema" para el breve sermón que el hermano Pedro pronuncia en las exequias del protagonista: "Esta letra está en el cielo / en las torres de su alcázar: / Dios humilla a los soberbios, / y los bumildes ensalza".

El caso de esta última pieza (datada en torno a 1511-1512) es paradigmático a propósito de esa filiación entre humildad y locura que venimos considerando. La principal biografía de san Juan de Dios -la debida a Francisco de Castro, publicada en Granada, en 1585- alude al famoso episodio en el que aquel, tras oír predicar a san Juan de Ávila, experimenta una profunda conversión, significada en algunos actos extremos:

En un lodazal que allí estaba se metió todo y se envolvió en él, y puesta la boca en el cieno, comenzó a grandes voces a confesar delante de todos los que le miraban (que era asaz gente) cuantos pecados se le acordaron [...] Toda la gente del vulgo, como vio esto, no creyeron sino que había

7. Para esta y las siguientes indicaciones cronológicas, Morley/Bruerton (y los datos aportados en Artelope: https://artelope.uv.es/). Me sirvo también de algunas útiles indicaciones de Morrison. 
perdido el juicio; mas como él estaba ya inflamado de la gracia del Señor, y deseaba morir por Él, y ser corrido y menospreciado de todos, para que lo pusiesen por obra, salido del lodo, comenzó a correr así como estaba por las calles más principales de la ciudad, dando saltos y haciendo muestras de loco. (VIII, fol. 21r)

Los desvaríos del santo le llevarán a ser ingresado en el Hospital Real de Granada, aunque la suya sea una "locura simulada", como demuestran con claridad las palabras de Castro: "Él se daba tan buena maña a fingir la locura, que realmente fue de casi todos tenido por loco" (VIII, 22v). Lope aborda el episodio en la escena final del primer acto de su comedia. Pero, a pesar de su afecto por el tema de la simulación, nada insinúa allí el Fénix a propósito de la condición "fingida" de esa demencia. ${ }^{8}$ Quizá sea lo de menos. Lo importante es que ha sabido ubicar ese pasaje, de manera incontestable, en la tradición de los "locos de Cristo":

$\begin{array}{ll}\text { JUAN } & \text { ¡No más mundo, no más honra! } \\ & \text { ¡Fuera locos desvaríos! } \\ & \text { Loco estoy de amor de Dios, } \\ & \text { que me entró por los oídos. } \\ & {[\ldots . .]} \\ \text { LOQUERO } & \text { ¿Quién eres? } \\ \text { JUAN } & \quad \text { Loco de Cristo. (vv. 1004-49) }\end{array}$

Es, en efecto, la rotundidad de ese último sintagma ("loco de Cristo"), sin precedente en la fuente, la que indica la necesidad de interpretar la escena a la luz del haz de motivos que informan ese tema hagiográfico, obligando, al paso, a interrogar su presencia en otras obras de Lope. Ninguna la hay de título más explícito, claro está, que Los locos por el cielo, aunque es preciso notar que ese rótulo adquiere connotaciones muy diversas, hilvanando todo un rosario de apariciones del tema de la locura en la comedia. De composición temprana (15981603), la pieza recrea la historia de los ya mencionados Domna e Indes, con los veinte mil mártires de Nicomedia, al parecer a partir del relato incluido por Villegas entre sus "extravagantes". ${ }^{9}$ El episodio de la comedia con una impreg-

8. Al propósito general del diseño de fuan de Dios y Antón Martín, Mazzocchi (y, en su edición de la pieza, la p. 1421).

9. Dos útiles acercamientos a la obra ofrecen Gola y Stoll. 
nación más evidente del tema de la locura es el que muestra a los dos protagonistas, recién convertidos, fingiéndose "locos sin remedio" ante sus perseguidores, para escapar de la ciudad. El propósito de esa insania simulada -salvaguardar la vida- se corresponde así con una de las variantes de la locura sagrada contempladas por Matthaeus Rader, amparada, por este último autor y por el mismo Lope, en el ejemplo omnipresente de David: "Divina local del cielo, / que como otro David sales / de los palacios reales, / de los peligros del suelo" (vv. 1642-45). Con todo, merece la pena reparar en el contenido de las palabras de esos dos alocados jóvenes para descubrir ya una segunda lectura, más trascendente y profunda, de la sagrada estulticia; a saber, el aspecto aparentemente absurdo de unos misterios sagrados en los que se cifra la verdadera sabiduría de Dios:

LICINIO Un Dios y personas tres, ¿no ves que a razón repugna?

[...]

DONA Corre el sol y resplandece, y da a la tierra calor, y el fuego también ofrece luz, movimiento y fervor, que así Agustín lo encarece; pues divide el sol y el fuego, y podrás lo mismo luego del uno y trino que adoro.

LICINIO Loca está. (vv. 1163-83)

Más allá de cualquier estratagema para la huida, la locura de Dona se erige así, como era cuestión en tantos otros simples y locos de Cristo, en vía para la declaración de una verdad superior, que desafía la razón humana, al amparo de la misma "locura de la Cruz" (“¿Y quién hay que no esté loco / viendo que Cristo da tanto / a los que le dan tan poco?”, vv. 1245-47). Por ese camino, la locura de Dona irá cobrando en la pieza un tercer matiz, para convertirse en aquella "demencia imputada" a los cristianos por los enemigos de la fe, a la que aludiera Rader. Una locura aparente, nacida del aspecto ilógico de la fe, pero también de su obstinada defensa hasta el martirio y la muerte. Una locura, en fin, compartida no solo por los dos protagonistas, sino por el conjunto de los veinte mil mártires, a los que ese título de "locos por el cielo" ya parece estar aludiendo: no otra cosa que un "pueblo loco y ciego" es, en efec- 
to, esa comunidad cristiana de Nicomedia encerrada en el templo, a la espera de la muerte.

Por lo demás, es obvio que la demencia -simulada o imputada, qué más da- de Dona e Indes es capaz de revelar en la obra toda la necedad que esconde la pretendida ciencia de los romanos, provocando una suerte de inversión de las apariencias -la sabia locura frente a la vana sabiduría- que, como aquel ensalzamiento de la humildad y abatimiento de la soberbia ya comentado, había de resultar especialmente grata a un teatro como el lopesco, sustentado en un fino juego de contrastes y paralelismos. Es justamente esa tensión entre el furor de unos y otros, de signo tan diverso, el que, como ya sucedía en los relatos martiriales de Surio y Villegas, favorecería la ocurrencia de todas las voces de la estulticia en la pieza; un texto que, acaso arrastrado por el peso de su título, todavía había de explorar los visos de una locura más mundana: aquella nacida del amor que siente por Dona el pagano Doroteo ("de razón falto" en tanto "ciego amante"), o la ocasionada en Indes por unos celos que son "locura del sufrimiento", pero que, al cabo, habrán de hacerle partir en busca de su amada y contemplar su maravilloso bautismo, descubriendo también así la verdad de Cristo: “¿Estos eran mis celos? / ¡Oh, celos siempre locos, / que haciendo bien a pocos, / hoy me daréis los cielos, / que abiertos los he visto!" (vv. 770-74).

\section{TEATROS DE LA SIMPLICIDAD}

Sería injusto ignorar lo que la presencia de la sagrada estulticia en las obras de Lope debe al aprecio general del autor por los motivos de la locura, la simulación y la inversión de las apariencias, que sustentan también muchas de sus obras profanas. ${ }^{10}$ Pero lo sería todavía más pasar por alto lo que ciertas escenas revelan acerca de su familiaridad con los arquetipos hagiográficos del loco y del simple de Cristo. Lope supo estar atento al atractivo sobre las tablas de esa última figura, delineada sobre los perfiles del humor inocente, el desprecio de sí mismo y una cándida ignorancia que -como la del niño- esconde la sabiduría más cierta. Mucho debe a esa querencia por los "santos simples" el diseño de algunas de sus comedias. Por ejemplo, la consagrada al franciscano san Benito de Palermo bajo el título de El santo negro Rosambuco, acaso redac-

10. Para el aprecio de Lope por el tema de la locura, Roso Díaz, Atienza, Thacker y López Martínez. 
tada antes de 1607 (es decir, apenas quince años después de la muerte del santo, acaecida en 1589). Benito, esclavo liberado sin apenas formación, no es personaje que se ajuste a la condición más extrema de la simplicidad -la nacida de una carencia del entendimiento-, pero sí responde al perfil del hombre iletrado, convertido en ejemplo de mansedumbre y servicio al prójimo. Así supo entenderlo su primer biógrafo, fray Antonio Daza:

Los padres de la provincia le hicieron guardián del Convento de Jesús de la ciudad de Palermo. Sintiolo mucho el bendito negro, pareciéndole que su condición y natural no era para mandar sino para servir a todos [...] Como este bendito negro y santo idiota se viese puesto en el candelero de la prelacía [...] no por ser guardián faltó un solo punto de los antiguos ejercicios de humildad y menosprecio en que se había criado; y así era muy continuo en la cocina y en la huerta, y el primero que tomaba la escoba para barrer el convento y servir a los otros padres. ${ }^{11}$

Lope, que no pudo basarse en la biografía de Daza, otorgó al protagonista el nombre de Rosambuco y la condición de corsario moro al servicio de los turcos. Su trayectoria en la obra contempla su conversión, su bautismo -con el nombre de Benito- y el ingreso en la orden franciscana, donde será fraile lego y más tarde guardián, condiciones aceptadas solo por obediencia. Es esta última la virtud esencial del santo, junto a la humildad extrema ("yo soy un tonto"), que le lleva a rechazar la veneración de su persona tras una milagrosa curación (“¿Quién se humilla / a un gusano como yo?”) y a vestirse de paciencia ante la envidia de su antagonista, Pedrisco: un donado que recibirá al protagonista con una inusitada violencia física y verbal ("perrazo", "padre mandinga modorro") y que aumentará su ira ante la elección de Benito ("idiota simple, sin ciencia") como guardián. Pedrisco tramará hacerse pasar por el santo ante el Virrey, para hacer "locuras de suerte y traza" que este "tenga allí al negro por loco". Pero ese plan tendrá un desenlace bien diferente, al convertirse milagrosamente en harina el tizne de la cara del perseguidor (redoblando así el juego de apariencias en el que se sustentaba la escena). Sea como fuere, el santo negro solicitará todavía ser humillado y pisoteado por su enemigo ("que suba luego a pisar / la boca y el pecho mío"), arrojándose al suelo y apelando a la obediencia, con la que Pedrisco cumplirá gustoso:

11. Para el texto de Daza (Cuarta Parta de la Crónica General de N. P. San Francisco, Valladolid, 1611, 66-68) y el problema de las fuentes, consúltese la ed. de Giuliano. Y añádanse Dell'Aira, Canonica y Morabito. 


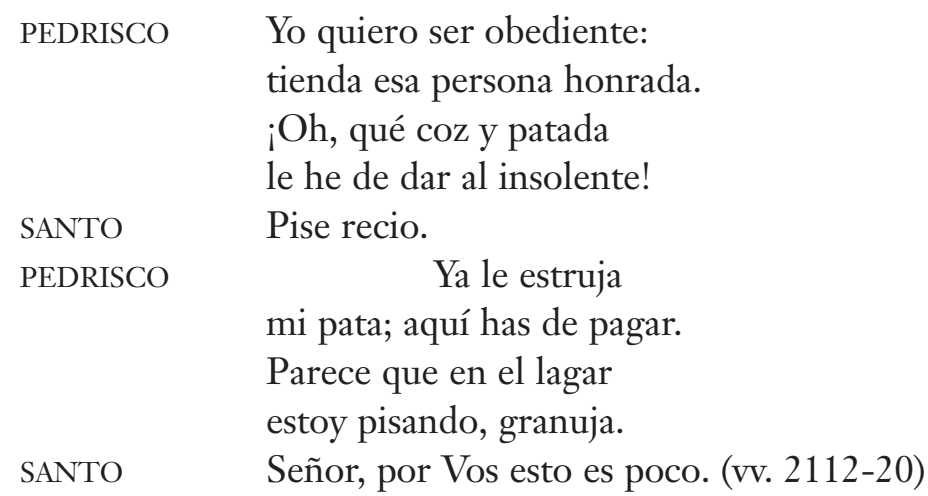

Es ese último verso el que otorga todo su sentido a tan curiosa escena -la imitación del Cristo humillado por sus verdugos-, según confirmaría Lope en el siguiente episodio, en el que el protagonista aparece elevado en contemplación, recorriendo con su vista las estaciones de la pasión y muerte en la cruz.

El elogio de la sencillez y la humildad sustenta también la escritura por parte del Fénix de su trilogía dramática sobre san Isidro. No faltan en la primera de esas piezas (el San Isidro, labrador de Madrid, finalizada verosímilmente entre 1604 y 1606) los reproches a ese labrador "ignorante" y "necio" por parte de algunos personajes engañados por la Envidia, alegoría que, por lo demás, no dudará en reconocer su derrota ante la "villana simpleza" del santo. Pero es condición esta última -la de la simplicidad- que muestra un perfil mucho más nítido (y ajustado a la tradición que nos ocupa) en una comedia de título elocuente, El rústico del cielo, escrita entre 1604 y 1605, es decir, en un momento muy cercano a la muerte del protagonista -el hermano fray Francisco del Niño Jesús, carmelita descalzo-, acaecida en la primera de esas fechas. Lope, que conoció personalmente al santo, celebra en la dedicatoria "aquella santa simplicidad" con la que llamaba a los reyes "el hermano Felipe y la hermana Margarita", pero también su obediencia, "materia en que se pudiera discurrir contra muchos, que no sabiendo, o no queriendo saber su valor, siguen fuera de ella su libertad". Desde los primeros versos, se advierte la extraña necedad de quien entra en escena, a la mañana, sin despertar del todo, pero habiendo soñado que volaba hacia el cielo. Francisco, que no duda en hablar con los árboles que tala, acabará matando, casi sin tener conciencia de ello, al guarda del monte, provocando los insultos de su mismo padre ("loco, ignorante, perdido"), quien habrá de enviarlo a la ciudad para evitar su castigo. En Alcalá, el joven proclamará su ignorancia, resumida en su incapacidad para aprender las primeras letras: "Señor mío, ¿qué os diré, / siendo yo tan ignorante, / 
que no he pasado delante / del Cbristus del abecé?” (vv. 624-27). Más allá de la literalidad de la expresión -que alude a la cruz que precede al abecedario o la cartilla de los niños-, la interrupción del aprendizaje de Francisco en ese "Christus" no puede sino recordarnos el caso de aquel Salauno que, como recordaba Rader, solo llegó a retener las palabras "Ave Maria". En ambos hombres, la ignorancia, cifrada en la detención de su pensamiento en esas palabras sagradas, es el primer signo de su santidad. El segundo signo, en el caso de Francisco, es la obediencia, que, al hilo de su "eterno voto" de devoción a la Natividad, expresa el santo simple con algunas imágenes de humillación extrema:

Yo vengo a serviros pronto;

no despreciéis mi rudeza;

porque suele ser grandeza

de un señor tener un tonto.

Un perro y un gato cría

un Príncipe; yo seré

perro, que quizá os traeré

caza que comáis un día.

Gato seré de infieles

con mis rústicas razones,

y cazaré los ratones

que roen vuestros papeles. (vv. 660-71)

"Gato" y "perro", como también "asno" y ser creado del "revés", Francisco es, por encima de todo, un niño ("que aunque a edad de hombre he llegado / niño en la inocencia soy", vv. 867-68). Expulsado por su torpeza de la Iglesia de San Justo y San Pastor en Alcalá (la de los "Santos Niños", justamente), el rústico protesta ante ambos con una deliciosa ingenuidad, recordando haber sido enseñado por otro "niño", al amparo de nuevo de la imagen del "Christus": "Señores niños, ¿por qué / de su casa me han echado, / si otro niño me ha enseñado / el Christus del abecé?" (vv. 837-40). Es la perenne "infancia" de Francisco del Niño Jesús la que legitima la elección de su nombre y la devoción por la Navidad. Esa devoción le llevará a organizar, en esas sagradas fechas, un reparto de alimentos en el hospital de Altozano, donde es enfermero mayor. Allí, un Niño Jesús es el encargado de custodiar y repartir el pan a los pobres, y con él conversa el santo, en una escena que invierte aquellos deliciosos episodios del Niño Dios alimentado por otros infantes "simples", que rememoraba, por 
esas mismas fechas, el jesuita Rader. El ambiente festivo y el protagonismo de los niños transporta al espectador, de un modo sutil, a esas fechas invernales de "obispillos" y "fiestas de locos" (Cox; Harris), con las que la obra comparte un idéntico afán por la subversión de la jerarquía del saber. El santo viajará a Madrid en busca de las limosnas de los reyes y los nobles, dialogando en su trayecto con las plantas de las huertas y dispuesto a celebrar, a la vuelta, una Nochebuena en la que él se reserva el papel de "mula" del pesebre, acompañando a un buey real, y rodeándose de "gran cantidad de niños y muchachos" (en una escena que acaso propiciara aquella subida habitual al escenario de "muchos niños de gente principal" a la que el propio Lope aludía en la dedicatoria de la pieza). La comedia se teje sobre esa devoción, infantil y navideña, que reserva todavía algún otro episodio entrañable, como aquel en el que Francisco consuela al Niño Dios ("Parece que hacéis pucheros! / ¡No, no, Niño, no haya más!”, vv. 2761-62), canta y baila unas seguidillas para alegrarle y le mece en la cuna, aunque es el santo el primero en dormirse. El propio Francisco predice su muerte para la Pascua de Navidad, según recuerda un Demonio tildado de "tiñoso" por el protagonista, y quejoso siempre de ese amparo divino al simple (que Dios, que "se sabe ajustar / a la condición del que ama / [...] / le imprime sus niñerías", vv. 2256-64). Un amparo que revela de nuevo la vanidad de la ciencia de los sabios: “ $\mathrm{OOh}$, gran libro Cristo, en quien / tan alta ciencia se aprende, / que algún sabio no la entiende, / y un rudo la entiende bien!” (vv. 2834-37).

Esos versos resumen un motivo central en la tradición de la estulticia sagrada, que también aflora, bajo presupuestos un tanto diversos, en la comedia dedicada por Lope, en torno a 1610-1612, a la figura de san Francisco de Asís: El serafín bumano. ${ }^{12}$ Por supuesto, esa figura ofrecía de suyo una concepción modélica -y ciertamente influyente- de la humildad simple y de la sagrada locura, que Lope supo realzar en la pieza. Las alusiones a la locura se suceden desde la misma conversión del santo, cuyos frutos -el afán de soledad, la entrega de los bienes- son interpretados por parte de sus amigos y de su propio padre como signo de una insania producida por las fiebres. Los mismos niños dan grita al santo (“iGuarda el loco, guarda el loco!”), que él acepta gustoso, apelando al desvarío de su vida anterior: "¡Oh, qué bien hacéis, tirad / al loco de la ciudad, / muchachos, tenelde en poco! [...] ¡Loco, mientras no vendía / la libertad que tenía / en la tienda del placer!" (26). Todo ello en una escena

12. Para una aproximación a la obra, léanse Aranda y Coll. 
cuyas imbricaciones con el tema que nos ocupa multiplican tanto la furia del padre, que golpea con saña al hijo ("Yo soy / el loco si no le doy / la muerte"), cuanto la reaparición sobre las tablas de un enigmático personaje: un "loco", justamente, que había profetizado al inicio de la pieza la santidad de Francisco y que ahora afeaba ese cruel trato paterno, estableciendo el consabido paralelismo con la violencia de los verdugos en la pasión de Cristo (27). Los arrebatos del santo no acaban allí. Ya en el acto segundo, tentado por la Carne, mortifica sus deseos de fundar una familia fabricando con nieve una mujer, cuatro hijos y dos criados, arrojándose al suelo entre ellos y azotando su cuerpo. En una escena posterior, vuelve a tenderse, para solicitar a fray Gil que ponga el pie sobre su pecho ("porque Dios los humildes engrandece", 39), algo que este último cumplirá por obediencia.

Con todo y con eso, el lugar que la sagrada estulticia ocupa en el diseño global de la obra tan solo se comprende desde la contemplación de una figura adicional: la de fray Junípero, que complementa, desde su condición de "simple", aquel perfil de "loco sagrado" adoptado por Francisco. Los actos y las palabras de Junípero delatan lo que sus compañeros entienden como "santa simplicidad": en una ocasión cocina todas las provisiones del convento, para saciar el hambre de los hermanos, de modo que puedan dedicar el resto del mes a rezar. En otra, regala su hábito a un pobre, quedando desnudo. Más adelante, recibe con desagrado la prohibición de repetir ese tipo de donaciones ("en no dejándome dar, / pienso que me vuelva loco", 56 y decide instar a un mendigo a que le robe, para salvar su voluntad de dar. Son actos de una "simplicidad dichosa", como entiende fray Gil, "lejos de la ciencia humana, / falsa, astuta y mentirosa" (42). Actos que revelan de nuevo una inversión del saber, un conocimiento otro, pero que lo hacen esta vez por la vía del humor, convirtiendo al santo en "gracioso de comedia" (Cazal).

Lope supo entender las posibilidades que la sagrada estulticia ofrecía en esa búsqueda de una honesta comicidad para su teatro; como conocía el resto de las claves de esa tradición hagiográfica, según revela una primera lectura de algunas de sus comedias de santos. Por supuesto, el hallazgo de las huellas de esa tradición debería extenderse a muchas otras piezas, algunas de ellas atribuidas, con mayor o menor fundamento, al propio autor: sin ir más lejos, dos de título tan explícito como El trubán del cielo y loco santo, que recrea de nuevo la figura de fray Junípero, y El saber por no saber, consagrada a San Julián de Alcalá. Sin duda, en esa labor de rastreo habrá también de prestarse atención a algunas comedias de autores posteriores. Piénsese en El lego de Alcalá, obra de 
Vélez de Guevara también dedicada a san Julián, en El loco cuerdo, San Simeón, de José de Valdivielso, o en La muerta viva y admirable Cristina, consagrada por José de Cañizares a la citada Cristina la Admirable. Es obvio que se trata de obras alejadas en el tiempo y dictadas por presupuestos estéticos muy diversos. Pero también lo es que tan solo desde la comprensión íntegra de la tradición de los "locos y simples de Cristo" habrá de entenderse cabalmente su sentido y su función en las letras barrocas.

\section{OBRAS CITADAS}

Aranda, María. "Lope de Vega: El serafín humano. Biographie d'une doublure". La Biographie dans le monde hispanique (XVIe-XXe siècles). Ed. J. Soubeyroux. Saint-Etienne: Université de Saint-Etienne, 2000. 91-108.

Atienza, Belén. El loco en el espejo: locura y melancolía en la España de Lope de Vega. Amsterdam: Rodopi, 2009.

Bigeard, Martine. La Folie et les fous littéraires en Espagne (1500-1650). Paris: Centre de Recherches Hispaniques, 1972.

Canonica, Elvezio. "La figura del negro santo y su contrapunto burlesco en $\mathrm{El}$ santo negro Rosambuco de Lope de Vega". Pratiques hagiographiques dans l'Espagne du Moyen Âge et du Siècle d'Or. Eds. F. Cazal, C. Chauchadis y C. Herzig. Toulouse: Université de Toulouse-Le Mirail, 2005. 301-13.

Cazal, Françoise. "Un gracioso de comedia de santos: fray Junípero en $E l$ serafin bumano de Lope de Vega". Pratiques hagiographiques dans l'Espagne du Moyen Âge et du Siècle d'Or. Eds. F. Cazal, C. Chauchadis y C. Herzig. Toulouse: Université de Toulouse-Le Mirail, 2005. 315-28.

Certeau, Michel de. La fábula mistica (siglos XVI-XVII). Madrid: Siruela, 2006.

Coll Sansalvador, Andreu. "De galán inadaptado a santo: las relaciones jerárquicas del santo con su entorno humano en El serafin bumano de Lope de Vega". Pratiques hagiographiques dans l'Espagne du Moyen Âge et du Siècle d'Or. Eds. F. Cazal, C. Chauchadis y C. Herzig. Toulouse: Université de Toulouse-Le Mirail, 2005. 213-19.

Cox, Harvey. Las fiestas de locos. Madrid: Taurus, 1983.

Dell'Aira, Alessandro. "Lope de Vega e un nero prodigioso". Quaderni della scuola italiana di Madrid 2 (1994): 117-35.

Derville, Andre. "Folie de la croix II: Dans la tradition". Dictionnaire de spiritualité. Ascétique et mystique: Doctrine et histoire. Vol. 5. Paris: Beauchesne, 1964. 645-50. 
Faius, Ioannes. Manipulus Exemplorum. Douay: Baltazar Bellerus, 1614.

Feuerstein, Georg. Holy Madness: The Shock Tactics and Radical Teachings of Crazy-Wise Adepts, Holy Fools and Rascal Gurus. New York: Paragon House, 1991.

Foucault, Michel. Historia de la locura en la época clásica. Vol. 1. México: FCE, 1976.

Gola, Carla. "Lope de Vega: Los locos por el cielo". Il confronto letterario 14 (1990): 347-63.

Gómez Moreno, Ángel. Claves hagiográficas de la literatura española (del "Cantar de mio Cid" a Cervantes). Madrid: Iberoamericana/Frankfurt am Main: Vervuert, 2008.

Gómez Moreno, Ángel. "Marcela y don Quijote: apuntes de hagiografía y cristología". Anales cervantinos 47 (2015): 355-70.

Harris, Max. Sacred Folly: A New History of the Feast of Fools. Ithaca, NY: Cornell UP, 2011.

Heisterbach, Cesáreo de. Illustrium miraculorum et historiarum memorabilium libri XII. Colonia: In Officina Birckmannica, sumptibus Arnoli Mylii, 1599.

Heisterbach, Cesáreo de. Diálogo de milagros. Ed. Z. Prieto Hernández. Zamora: Monte Casino, 1998.

Ignacio de Loyola. Obras. Madrid: BAC, 1991.

Ivanov, Sergey A. Holy Fools in Byzantium and Beyond. New York: Oxford UP, 2008.

Juan Clímaco. Escala Spiritual. Lisboa: Ioannes Blavio, 1562.

Lipomano, Luis, y Lorenzo Surio. De probatis sanctorum historiis. Colonia: Gervinus Calenius et haeredes Quintelios, 1570-1577.

López Martínez, José Enrique. "Locos y bobos fingidos: otra forma de representar (sin disfraz) en el teatro de Lope de Vega". Atalanta: Revista de las Letras Barrocas 2 (2014): 53-95.

Lukas, Veronika. "Rader, Matthaeus". Brill's New Pauly Supplements I. Volume 6: History of classical Scholarship. A Biographical Dictionary. English ed. by Chad M. Schroeder (2014). 7 de abril de 2019. <http://dx.doi.org/10. 1163/2214-8647_bnps6_COM_00586>.

Magnum Speculum Exemplorum. Ed. Ioannes Maior. Duaci: Baltazar Bellerus, 1614.

Márquez Villanueva, Francisco. "Un Aspect de la littérature du «fou» en Espagne". L'Humanisme dans les lettres espagnoles. Ed. A. Redondo. Paris: Vrin, 1979. 235-50. 
Márquez Villanueva, Francisco. "Literatura bufonesca o del loco". Nueva Revista de Filología Hispánica 24.2 (1985-1986): 501-27.

Mateo Palacios, Ana. "Estudio introductorio". Las vidas de los sanctos religiosos de Egipto, traducidas por micer Gonzalo García de Santa María. Zaragoza: Institución "Fernando el Católico", 2015. 7-144.

Mazzocchi, Giuseppe. "Juan de Dios y Antón Martín de Lope de Vega: análisis de los mecanismos de una comedia de santos". Teatro del Siglo de Oro: bomenaje a Alberto Navarro González. Ed. V. García de la Concha y otros. Kassel: Reichenberger, 1990. 407-35.

Mollat, Donatien. "Folie de la croix I: Dans l'Écriture Sainte". Dictionnaire de spiritualité. Ascétique et mystique. Doctrine et histoire. Vol. 5. Paris: Beauchesne, 1964. 636-44.

Morabito, María Teresa. "Un santo siciliano en la escena teatral española del Siglo de Oro: El santo negro Rosambuco de la ciudad de Palermo, de Lope de Vega". Cuatrocientos años del Arte Nuevo de hacer comedias de Lope de Vega. Eds. G. Vega García-Luengos y H. Urzáiz Tortajada. Olmedo: Festival de Olmedo, 2010. 747-56.

Morley, S. Griswold, y Courtney Bruerton. Cronología de las comedias de Lope de Vega. Madrid: Gredos, 1968.

Morrison, Robert R. Lope de Vega and the "Comedia de santos". New York: Peter Lang, 2000.

Rader, Matthaeus. Viridarii Sanctorum Pars Prima, ex Menaeis Graecorum lecta et translata. Monachii: Anna Berg, 1614.

Rader, Matthaeus. Viridarii Sanctorum Pars Altera. De simplici obedientia et contemptu sui, cum auctario de quorundam simplicium dictis et factis. Monachii: Anna Berg, 1614.

Rader, Matthaeus. Viridarii Sanctorum Pars Tertia. Continet Illustria Sanctorum Exempla ex Graecis et Latinis Scriptoribus depromta. Monachii: Anna Berg, 1614.

Redondo, Jordi. “An Eastern Tradition in Lullian Blaquerna: The Holy Fool Ramon lo Foll”. Pbilologia Classica 12 (2017): 206-17.

Redondo, Augustin, y André Rochon, eds. Visages de la folie (1500-1650) (domaine hispano-italien). Paris: Publications de la Sorbonne, 1981.

Roso Díaz, José. "El enredo de los locos en las comedias de Lope de Vega". Locos, figurones y quijotes en el teatro de los Siglos de Oro. Eds. G. Vega García-Luengos y R. González Cañal. Almagro: UCLM, 2007. 425-40.

Sanctoro, Juan Basilio. Prado Espiritual recopilado de autores antiguos clarísimos. Madrid: Andrés García, 1674. 
Saward, John. Dieu à la folie: Histoire des saints fous pour le Christ. Paris: Seuil, 1983. Schmid, Alois. "Pädagoge, Philologe, Historiograph: P. Mattäus Rader". Literaturgeschichte Münchens. Eds. W. Fromm, M. Knedlik y M. Schellong. Regensburg: Friedrich Pustet, 2019. 152-58.

Špidlík, Thomas. "Fous pour le Christ I: en Orient”. Dictionnaire de spiritualité. Ascétique et mystique. Doctrine et histoire. Vol. 5. Paris: Beauchesne, 1964. 752-61.

Stoll, Anita K. "Staging, Metadrama and Religion in Lope's Los locos por el cielo". Neophilologus 78 (1994): 233-41.

Swain, Barbara. Fools and Folly During the Middle Ages and the Renaissance. New York: Columbia UP, 1932.

Thacker, Jonathan. "La autoridad de la figura del loco en las comedias de Lope de Vega". Autoridad y poder en el Siglo de Oro. Eds. I. Arellano, C. Strosetski y E. Williamson. Madrid: Iberoamericana/Frankfurt am Main: Vervuert, 2009. 175-88.

Vandenbroucke, François. "Fous pour le Christ II: en Occident". Dictionnaire de spiritualité. Ascétique et mystique. Doctrine et histoire. Vol. 5. Paris: Beauchesne, 1964. 761-70.

Vega Carpio, Lope de. El serafín humano. Obras de Lope de Vega, X: Comedias de vidas de santos II. Ed. M. Menéndez Pelayo. Madrid: Atlas, 1965. 7-68.

Vega Carpio, Lope de. El santo negro Rosambuco de la ciudad de Palermo. Ed. L. Giuliani. Comedias de Lope de Vega. Parte III. Coord. L. Giuliani. Lérida: Milenio, 2002. 397-501.

Vega Carpio, Lope de. San Isidro, labrador de Madrid. Ed. M. Morrás. Comedias de Lope de Vega. Parte VII. Vol. 3. Coord. E. Di Pastena. Lérida: Milenio, 2008. 1521-658.

Vega Carpio, Lope de, Los locos por el cielo. Ed. E. Bassegoda i Pineda. Comedias de Lope de Vega. Parte VIII. Vol. 1. Coord. R. Ramos. Lérida: Milenio, 2009. 305-427.

Vega Carpio, Lope de. La bumildad y la soberbia. Ed. M. Zugasti. Comedias de Lope de Vega. Parte X. Vol. 1. Coords. R. Valdés y M. Morrás. Lérida: Milenio, 2010. 485-621.

Vega Carpio, Lope de. Fuan de Dios y Antón Martín. Ed. G. Mazzocchi. Comedias de Lope de Vega. Parte X. Vol. 3. Coords. R. Valdés y M. Morrás. Lérida: Milenio, 2010. 1365-508.

Vega Carpio, Lope de. La hermosa Ester. Ed. J. Aragüés Aldaz. Comedias de Lope de Vega. Parte XV. Vol. 2. Coord. L. Sánchez Laílla. Madrid: Gredos, 2016. 3-269. 
Vega Carpio, Lope de. El rústico del cielo. Ed. J. Llamas. Comedias de Lope de Vega. Parte XVIII. Vol. 2. Coords. A. Sánchez Jiménez y A. J. Sáez. Madrid: Gredos, 2019. 615-794.

Villegas, Alonso de. Flos Sanctorum y Historia General de la Vida de Fesucristo. Toledo: Blas de Robles y Juan Rodríguez, 1582.

Villegas, Alonso de. Flos Sanctorum. Segunda Parte y Historia General en que se escribe la Vida de la Virgen. Barcelona: Juana Manescala, 1589.

Villegas, Alonso de. Flos Sanctorum. Tercera Parte y Historia General en que se escriben las Vidas de sanctos extravagantes. Zaragoza: Lorenzo de Robles, 1582.

Villegas, Alonso de. Flos Sanctorum. Cuarta Parte, y Discursos o Sermones. Barcelona: Jaime Cendrat, 1603.

Villegas, Alonso de. Fructus Sanctorum, y Quinta Parte del Flos Sanctorum. Ed. J. Aragüés Aldaz. Lemir: revista de literatura española medieval y del Renacimiento 2 (1998). 10 de abril de 2019. <https: //parnaseo.uv.es/Lemir/ Textos/Flos/Index1.html>. 
SECCIÓN MISCELÁNEA 
